do quá trình hoại tử u. Trong đó, cơ chế giải thích chính là cơ chế thiếu oxy gây nhồi máu trong $u$.

\section{KẾT LUÂ̂N}

Cộng hưởng từ thường quy với hình ảnh T1W, T2W và T1 sau tiêm không có giá trị trong phân biệt UMN lành/ác tính.

Trên hình ảnh DWI, UMN ác tính/không điển hình có tỷ lệ hạn chế khuếch tán nhiều hơn so với UMN lành tính. Do đó, $\mathrm{CHT}$ khuếch tán là xung có giá trị giúp dự đoán tính chất lành tính/ác tính của UMN trước phẫu thuật.

\section{TÀI LIỆ THAM KHẢO}

1. Elizabeth B. Claus, Melissa L. Bondy, Joellen M. Schildkraut. et al. (2005), "Epidemiology of Intracranial Meningioma". Neurosurgery, 57(6), pp. 1088-1095.

2. F. Salah, A. Tabbarah, N. Alarab y. et al. (2019), "Can CT and MRI features differentiate benign from malignant meningiomas?". Clinical Radiology, 74(11), pp. 898.e15-898.e23.
3. C. Mawrin,A. Perry (2010), "Pathological classification and molecular genetics of meningiomas". J Neurooncol, 99(3), pp. 379-91.

4. Lê Thị Hông Phương (2016). Đặc điểm hình ảnh cộng hưởng từ và mổi liên quan với triệu chứng lâm sàng của u màng não nền sọ. Luận văn tốt nghiệp Bác sĩ Nội trú, Đại học Y Hà Nội.

5. Antonios Drevelegas (2010), Imaging of brain tumors with histological correlations,Springer Science \& Business Media

6. T. Zhang, J. M. Yu, Y. Q. Wang. et al. (2018), "WHO grade I meningioma subtypes: MRI features and pathological analysis". Life Sci, 213, pp. 50-56.

7. B. J. Lin, K. N. Chou, H. W. Kao. et al. (2014) "Correlation between magnetic resonance imaging grading and pathological grading in meningioma". 1 Neurosurg, 121(5), pp. 1201-8.

8. Nguyến Thị Bảo Ngọc, Đặng Nguyễn Trung An, Trần Quang Vinhi. et àl. (2013), "Khảo sát đăc điểm hình ảnh cộng hưởng từ của u màng não nội sọ". Y học Thành phố Hồ Chí Minh, 17(1), pp. 500-503.

9. D. M. Sohu, S. Sohail,R. Shaikh (2019), "Diagnostic accuracy of diffusion weighted MRI in differentiating benign and malignant meningiomas". Pak J Med Sci, 35(3), pp. 726-730.

\title{
HIÊUU QUẢ CỦA DỤNG CỤ TỬ CUNG MIRENA TRONG ĐIỀU TRỊ MộT Số BÊ̂NH LÝ LÀNH TÍNH CỦA TỬ CUNG
}

\author{
Hà Duy Tiến ${ }^{1}$, Phạm Thị Tân ${ }^{1}$, Nguyễn Ngọc Phương ${ }^{1}$, \\ Phạm Thị Thanh Hiền ${ }^{2}$, Đào Văn Thụ ${ }^{1}$, Bùi Lê Khánh Chi ${ }^{1}$
}

\section{TÓM TẮT}

Mục tiêu: Nhận xét hiệu quả giảm đau và giảm ra máu của DCTC Mirena trong điều tri môt số bênh lý lành tính của tử cung. Đối tượng và phương pháp nghiên cứu: mô tả tiến cứu trên nhửng bệnh nhân có triệu chứng thống kinh và cường kinh được điều trị bằng DCTC Mirena, đánh giá hiệu quả sau 6 tháng sư dụng. Kết quả: Có 55 bệnh nhân được đặt DCTC Mirena để điêu trị, điểm đánh giá mức độ đau theo thang điểm VAS giảm từ 5,9 \pm 4,3 xuống 1,4 $\pm 2,4$, trong đó cải thiện rõ rệt ở nhóm đau khưng khiếp và đau nặng. Số ngày ra máu trung bình thay đổi không có ý nghĩa thống kê $(p=0,885)$, tuy nhiên tỷ lệ vô kinh tăng từ $3,6 \%$ lên $12,7 \%$ và ra máu kéo dài tăng từ $23,7 \%$ lên $40 \%$. Số lượng máu mất giảm đáng kể, đăc biệt ở nhóm ra máu nhiêu và trung binh. Kết luận: DCTC Mirena là phương pháp hiệu quả điều trị giảm đau và giảm ra máu trong các bệnh lý lành tính của tử cung.

\footnotetext{
${ }^{1}$ Bệnh viện Phụ Sản Trung Uơng

¿Đại họ Y Hà Nội

Chịu trách nhiệm chính: Nguyễn Ngọc Phương

Email: pika.hmu@gmail.com

Ngày nhận bài: 4.5.2021

Ngày phản biện khoa học: 25.6.2021

Ngày duyệt bài: 6.7.2021
}

Tư khóa: Dụng cụ tử cung (DCTC), Mirena, thống kinh, cường kinh.

\section{SUMMARY \\ THE EFFICACY OF MIRENA IN TREATMENT OF SOME BENIGN UTERINE DISEASES}

Objectives: To review the effects of the IUD Mirena in treatment of some benign uterine diseases, particularly in reducing menstrual blood loss and dysmenorrhea. Subjects and Methods: prospective description of patients with dysmenorrhea and menorrhagia treated with Mirena, and evaluation of results after 6 months of use. Results: 55 patients were inserted Mirena. The assessment score of pain on the VAS scale decreased from $5.9 \pm 4.3$ to $1.4 \pm$ 2.4 and a greater and more significant mean reduction occurred in the worst pain possible and very severe pain group. The mean number of bleeding days was not statistically significant $(p=0.885)$, but the rate of amenorrhea increased from $3.6 \%$ to $12.7 \%$, and prolonged bleeding rate increased from $23.7 \%$ to $40 \%$. The amount of blood loss decreased markedly, especially in the heavy and moderate bleeding groups. Conclusion: Mirena IUD is an effective treatment to alleviate the pain and reduce menstrual blood loss in some benign uterine diseases.

Keywords: Intrauterine device (IUD), Mirena, dysmenorrhea, menorrhagia. 


\section{I. ĐẶT VẤN ĐỀ}

Triệu chứng cường kinh và thống kinh trong các bệnh lý lành tính của tử cung là lý do chính khiến người phụ nữ đến khám, ảnh hưởng nghiêm trọng tới chất lượng cuộc sống. Điều trị nội khoa giúp bảo tồn tử cung, cải thiện triệu chứng và tiến triển của bệnh. Tuy nhiên thuốc uống tác dụng toàn thân nên hiệu quả hạn chế và có nhiêu tác dụng phụ nễu sử dụng kéo dài. Dụng cụ tử cung Mirena phóng thích Levonogestrel có tác dụng tại chỗ, ức chế tăng sinh nội mạc tử cung do đó hiệu quả cao trong việc giảm các triệu chứng của chu kỳ kinh nguyệt, ít tác dụng toàn thân [1]. DCTC Mirena được đưa vào sử dụng ở nước ta từ những năm 2010, tuy nhiên chưa có nhiều nghiên cứu về những tác dụng ngoài tránh thai của dụng cụ này. Do đó chúng tôi tiến hành nghiên cứu: "Hiệu quả của dụng cu tử cung Mirena trong điều trị một số bệnh lý lành tính của tử cung" với mục tiêu: Nhận xét hiệu quả giảm đau và giảm ra máu của DCTC Mirena trong điều trị một sô bệnh lý lành tính của tử cung.

\section{II. ĐỐI TƯỢNG VÀ PHƯƠNG PHÁP NGHIÊN CỨU}

2.1. Đối tượng nghiên cứu. Nghiên cứu được thực hiện tại trung tâm TVSKSS-KHHGĐ từ tháng 1 năm 2019 đến tháng 3 năm 2020 trên các bệnh nhân có chỉ định đặt DCTC Mirena để điều trị, bao gồm: thống kinh và cường kinh cơ năng, lạc nội mạc trong cơ tử cung, u xơ tử cung $(<4 \mathrm{~cm})$ và quá sản lành tính niêm mạc tử cung.

\subsection{Phương pháp nghiên cứu}

Mô tả tiến cứu, đánh giá hiệu quả sau 6 tháng đặt DCTC Mirena.

- Tiêu chuẩn đánh giá mức độ đau: theo thang điểm VAS (Visual Analogue Scale), người bệnh lựa chọn mức độ đau từ 0 đến 10 điểm [2], với các nhóm: không đau (0 điểm), đau nhẹ (1 - 3 điểm), đau trung bình ( $4-6$ điểm), đau nặng (7 - 9điểm) và đau khủng khiếp (10 điểm).

- Đánh giá thời gian ra máu: vô kinh, ra máu kéo dài ( $>8$ ngày), trung bình (4,5-8 ngày) và ngắn ( $<4,5$ ngày).

- Đánh giá số lượng máu mất:

Thuật ngữ cường kinh theo NICE là hiện tượng ra máu nhiều khi hành kinh và ảnh hưởing tới thể chất và đời sống người phụ nữ [3], sau đó được thay bằng thuật ngữ ra máu kinh nhiều (theo FIGO [4]).

Ra máu nhiều được định lượng trên $80 \mathrm{ml}$, lượng máu ra nhiều hơn ngày có kinh nhiều nhất, tương đương $\geq 6$ băng vệ sinh/ngày.

Lượng máu kinh trung bình khi thể tích máu mất $5-80 \mathrm{ml}$, tương đương những ngày giữa chu kỳ ( $3-4$ băng vệ sinh/ngày).

Lượng máu kinh ít với thể tích máu mất < $5 \mathrm{ml}$, tương đương hành kinh ngày cuối $(1-2$ băng vệ sinh/ngày).

\section{KẾT QUẢ NGHIÊN CỨU}

Nghiên cứu thu được 55 bệnh nhân thỏa mãn tiêu chuẩn nghiên cứu.

Bảng 1. Đăc điểm của đôî tượng nghiên cứu

\begin{tabular}{|c|c|c|}
\hline Đăc điếm & Số lượng & Tỷ lệ \% \\
\hline Tuối trung bình & \multicolumn{2}{|c|}{$40,3 \pm 5,4$} \\
\hline \multicolumn{3}{|c|}{ Nghề nghiệp } \\
\hline Cán bộ viên chức & 32 & 58,2 \\
\hline Công nhân, lao động & 10 & 18,2 \\
\hline Tự do & 13 & 23,6 \\
\hline \multicolumn{3}{|c|}{ Tiền sử sinh } \\
\hline 1 & 9 & 16,4 \\
\hline$\geq 2$ & 46 & 83,6 \\
\hline \multicolumn{3}{|c|}{ Tiên sử sảy phá thai } \\
\hline 0 & 18 & 32,7 \\
\hline 1 & 10 & 18,2 \\
\hline$\geq 2$ & 27 & 49,1 \\
\hline
\end{tabular}

3.1. Đặc điếm chung. Các đặc điếm chung của nhóm đối tượng nghiên cứu (tuổi, nghề nghiệp và tiền sử sản khoa) được mô tả trong bảng 1 .

3.2. Hiệu quả giảm đau. Mức độ đau được đánh giá theo thang điểm VAS và chia thành các mức độ đau (bảng 2). Chúng tôi so sánh mức độ đau của bệnh nhân sau 6 tháng đặt DCTC Mirena cho thấy điểm VAS trung bình và của nhóm đau khủng khiếp và đau nặng đều giảm rõ rệt.

Bảng 2. Hiệu quả giảm đau

\begin{tabular}{|c|c|c|c|}
\hline 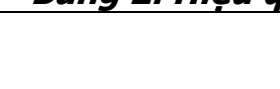 & $\begin{array}{c}\text { Trước } \\
\text { đặt }\end{array}$ & $\begin{array}{l}\text { Sau } \\
\text { đặt }\end{array}$ & $\mathbf{P}$ \\
\hline Giá trị điểm VAS & $\begin{array}{c}5,9 \pm \\
4,3\end{array}$ & $\begin{array}{c}1,4 \pm \\
2,4\end{array}$ & $\begin{array}{c}0,00< \\
0,01\end{array}$ \\
\hline \multicolumn{4}{|c|}{ Mức độ đau } \\
\hline Đau khủng khiếp & $41,8 \%$ & $1,8 \%$ & \\
\hline Đau nặng & $14,6 \%$ & $7,3 \%$ & \\
\hline Đau trung bình & $7,3 \%$ & $5,5 \%$ & \\
\hline Đau nhẹ & $12,7 \%$ & $30,9 \%$ & \\
\hline Không đau & $23,6 \%$ & $54,5 \%$ & \\
\hline
\end{tabular}

3.3. Hiệu quả giảm ra máu

3.3.1. Số ngày ra máu. Số ngày ra máu trung bình và kiểu ra máu của mỗi chu kỳ kinh trước và sau khi đặt DCTC Mirena được ghi nhận trong bảng sau.

Bảng 3. Sốngày ra máu trước và sau đặt

\begin{tabular}{|c|c|c|c|}
\hline & & & \\
\hline & Trước đặt & Sau đặt & $\mathbf{P}$ \\
\hline Số ngày ra máu & $7,6 \pm 5,8$ & $8,2 \pm 7,7$ & 0,885 \\
\hline & Kiểu ra m & & \\
\hline Vô kinh & $3,6 \%$ & $12,7 \%$ & \\
\hline Ngắn & $18,2 \%$ & $12,7 \%$ & \\
\hline
\end{tabular}




\begin{tabular}{|c|c|c|}
\hline Trung bình & $54,5 \%$ & $34,5 \%$ \\
\hline Kéo dài & $23,7 \%$ & $40 \%$ \\
\hline
\end{tabular}

3.3.2. Số Iương máu mất. Số lượng máu mất mỗi chu kỳ được đánh giá một cách tương đối thông qua kiểu ra máu và số lượng băng vệ sinh, so sánh trước và sau khi đặt DCTC Mirena.

Bảng 4. Thay đổi số lượng máu mất

\begin{tabular}{|c|c|c|}
\hline & Trước đặt & Sau đặt \\
\hline Ra kinh nhiều & $58,2 \%$ & $10,9 \%$ \\
\hline Trung bình & $29,1 \%$ & $10,9 \%$ \\
\hline It & $7,3 \%$ & $47,3 \%$ \\
\hline Thấm giọt & $1,8 \%$ & $18,2 \%$ \\
\hline Vô kinh & $3,6 \%$ & $12,7 \%$ \\
\hline
\end{tabular}

\section{BÀN LUÂNN}

Đặc điểm chung. Tuổi trung bình của các phụ nữ trong nghiên cứu là 40,3 $\pm 5,4$, tương tự nghiên cứu của Lee K.H. (2016), Magalhaes J. (2007) và Varma R. (2008) về lạc nội mạc, u xơ tử cung và quá sản niêm mạc tử cung [5-7]. Điều này phù hợp với độ tuổi xuất hiện các triệu chứng rối loạn kinh nguyệt hoặc bệnh lý lành tính của tử cung. Nhóm nghề nghiệp viên chức chiếm tỷ lệ cao nhất $(58,2 \%)$ có thể do sự mới và giá thành của DCTC Mirena nên đối tượng tiếp cận được là những người có trình độ và thu nhập cao hớn.

Đa số bệnh nhân đã có 2 con trở lên (chiếm $83,6 \%$ ) cho thấy các bệnh nhân lựa chọn DCTC khi đã đủ con. Tiền sử hút thai nhiều lần chiếm tỷ lệ cao gợi ý mối liên quan của yếu tố này. Có thể việc nạo hút thai làm tăng nguy cơ bệnh tuyến cơ tử cung phù hợp với giả thuyết về sinh lý bệnh của tình trạng lạc nội mạc trong cơ tử cung là từ sự xâm nhập thồng qua sự không toàn vẹn của vùng chuyển tiếp tứ cung hoặc tổn thương vùng chức năng tử cung sau quá trình nạo hút thai và viêm niêm mạc tử cung [8].

Hiệu quả giảm đau. Sau 6 tháng đặt DCTC Mirena, điểm VAS trung bình đánh giá mức độ đau đã giảm có ý nghĩa $(p=0,00<0,01)$. Giảm đau nhiều nhất ở nhóm đau khủng khiếp và đau nặng. Chúng tôi nhận thấy sự giảm đau rõ rệt xuất hiện sau khi đặt DCTC 1 tháng. Theo Lee K.H. (2016), DCTC Mirena giúp làm giảm đau hiệu quả trên các bệnh nhân bệnh tuyến cơ tử cung [5]. Tương tự một nghiên cứu của Radzinsky V.E. (2016) về thống kinh do bệnh tuyến cơ tử cung, tác giả nhận thấy nhóm đau nhẹ có $20 \%$ bệnh nhân cải thiện sau tháng đâuu tiên, $66,3 \%$ cải thiện ở tháng thứ 2 và $16,65 \%$ còn lại cải thiện vào sau tháng thứ 3 và giảm đau hoàn toàn được xác nhận sau 3 tháng theo dõi [9].

Hiệu quả giảm ra máu. Theo bảng 3, số ngày ra máu trung bình trước và sau khi đặt DCTC không có sự khác biệt $(p=0,885)$. Tuy nhiên tỷ lệ bệnh nhân vô kinh và rong kinh đều tăng lên. Đây là những tác dụng có thể gặp của DCTC chứa levonorgestrel cũng như các biện pháp tránh thai nội tiết tác dụng kéo dài nói chung [5] do đó cần tư vấn cho bệnh nhân trước khi đặt DCTC đồng thời hướng dẫn bệnh nhân tái khám để điều trị khi có ra máu kéo dài. Mặt khác, số lượng máu mất trung bình đặc biệt là những trường hợp ra máu mức độ nhiều và trung bình đã giảm rõ rệt sau 6 tháng đặt Mirena (bảng 4). Tình trạng ra máu nhiêu ảnh hưởng lớn đến thể chất cũng như chất lượng cuộc sống của bệnh nhân đã được khắc phục, đây cũng là một tác dụng to lớn của DCTC-levonorgestrel. Nghiên cứu của tác giả Bahamondes L. (2007) cũng cho thấy DCTC giải phóng nội tiết có tác dụng giảm lượng máu kinh nguyệt rõ rệt trên các bệnh nhân lạc nội mạc tử cung cũng như cải thiện tình trạng đau vùng chậu mạn tính.

Nghiên cứu của chúng tổi đánh giá kết quả tại thời điểm sau đặt DCTC 6 tháng nên chưa thể hiện rõ diễn biến hiệu quả giảm đau và giảm ra máu ở các thời điểm. Hơn nữa, dù mức độ ra máu giảm nhưng số trường hợp ra máu kéo dài tăng lên, tuy nhiên hiện tượng này có thể cải thiện với các điều trị nội khoa giúp giảm tỷ lệ tháo DCTC trước thời hạn. Đây là những vấn để có thể tiếp tục được làm rõ trong những nghiên cứu tiếp theo.

\section{KẾT LUẬN}

Dụng cụ tử cung Mirena là một biện pháp hiệu quả trong điêu trị các triệu chứng đau bụng và ra máu nhiều trên các bệnh lý lành tính của tử cung.

\section{TÀI LIÊU THAM KHẢO}

1. P. Zhu, H. Luo, J. Cheng và cộng sự (1989) The effect of intrauterine devices (stainless steel ring, Copper-T220 and levonorgestrel) on the DNA content in isolated human endometrial cells. Contraception, 40 (5), 591-604.

2. G. A. Hawker, S. Mian, T. Kendzerska và cộng sự (2011). Measures of adult pain: Visual Anàlog Scale for Pain (VAS Pain), Numeric Rating Scale for Pain (NRS Pain), McGill Pain Questionnaire (MPQ), Short-Form McGill Pain Questionnaire (SF-MPQ), Chronic Pain Grade Scale (CPGS), Short Form-36 Bodily Pain Scale (SF-36 BPS), and Measure of Intermittent and Constant Osteoarthritis Pain (ICOAP). Arthritis Care Res (Hoboken), 63 Suppl $11, \mathrm{~S} 240-252$.

3. L. A. Douglass và A. M. Davis (2020). Assessment and Management of Heavy Menstrual Bleeding. JAMA, 323 (3), 270-271.

4. M. G. Munro, H. O. D. Critchley, M. S. Broder 
và cộng sự (2011). FIGO classification system (PALM-COEIN) for causes of abnormal uterine bleeding in nongravid women of reproductive age. International Journal of Gynecology \& Obstetrics, 113 (1) 3-13.

5. K. H. Lee, J. K. Kim, M. A. Lee và cộng sự (2016). Relationship between uterine volume and discontinuation of treatment with levonorgestrelreleasing intrauterine devices in patients with adenomyosis. Archives of Gynecology and Obstetrics, 294 (3), 561-566.

6. J. Magalhães, J. M. Aldrighi và G. R. de Lima (2007). Uterine volume and menstrual patterns in users of the levonorgestrel-releasing intrauterine system with idiopathic menorrhagia or menorrhagia due to leiomyomas. Contraception,
75 (3), 193-198.

7. R. Varma, H. Soneja, K. Bhatia và cộng sứ (2008). The effectiveness of a levonorgestrelreleasing intrauterine system (LNG-IUS) in the treatment of endometrial hyperplasia-A long-term follow-up study. European Journal of Obstetrics \& Gynecology and Reproductive Biology, 139 (2), 169-175.

8. J. Struble, S. Reid và M. A. Bedaiwy (2016). Adenomyosis: A Clinical Review of a Challenging Gynecologic Condition. Journal of Minimally Invasive Gynecology, 23 (2), 164-185.

9. V. E. Radzinsky, M. B. Khamoshina, E. N. Nosenko và cộng sự (2016). Treatment strategies for pelvic pain associated with adenomyosis. Gynecological Endocrinology, 32 (sup2), 19-22.

\section{ĐÁNH GIÁ KẾT QUẢ THAY LẠI KHỚP HÁNG NHÂN TẠO TẠI BỆNH VIỆN VIỆT ĐỨC TỪ NĂM 2015 ĐẾN 2018}

\section{TÓM TẮT}

Thay khớp háng nhân tão phát triển tại nước ta khoảng trên 15 năm nay. Mỗi khớp háng nhân tạo có tuổi thọ nhất định nên khớp háng nhân tạo có thể bị hỏng. Việc chỉ đinh và đưa ra phương pháp thay lai khớp háng phải được nghiên cứu. Mục tiêu: Đánh giá kết quả thay lại khớp háng nhân tạo. Đối tượng và phương pháp: Nghiên cứu can thiệp lâm sàng 23 trường hợp hỏng khớp háng nhân tao được thay lai khớp háng từ năm 2015 đến 2018 tại Bệnh viện Việt Đức. Kết quả: Có 20 trường hợp hỏng khớp do lỏng ổ cối hoăcc lỏng chuôi khớp, hoặc mòn ổ cối; 3 trường hợp hỏng khớp do gãy dưới chuôi và gãy cổ chuối khớp được thay lại khớp háng. 9 khớp háng thay lại toàn phần, 6 khớp thay lại ố cối và 8 khớp thay lại chuôi khớp. Chức năng khớp háng cải thiên đáng kể với 17 trường hợp đạt kết quả tốt, 6 trường hợp đạt kết quả khá. Kết luận: Phát hiện sớm hiện tượng hỏng khớp háng, thay lai khớp háng phù hợp giúp cải thiện chức năng khớp háng cho bệnh nhân.

Tư khóa: thay lại khớp háng nuhân tạo.

\section{SUMMARY}

EVALUATE THE RESULTS OF REVISION HIP ARTHROPLASTY AT VIET DUC HOSPITAL FROM 2015 TO 2018

Hip arthroplasty has developed in our country for 15 years. Each artificial hip has longevity and is gradually defective so revision hip arthroplasty has to

\footnotetext{
${ }^{1}$ Bệnh viện Việt Đức

${ }^{2}$ Dai hoc Y Hà Nôi

Chịu trách nhiệm chính: Trân Mạnh Hùng

Email: drhung30@gmail.com

Ngày nhận bài: 7.5.2021

Ngày phản biện khoa học: 25.6.2021

Ngày duyệt bài: 6.7.2021
}

\section{Trần Mạnh Hùng ${ }^{1}$, Nguyễn Xuân Thuỳ ${ }^{2}$}

be studied. Objective: To evaluate the results of revision hip arthroplasty. Patients and methods: An interventional study included 23 cases who had damaged artificial hip underwent revision hip arthroplasty from 2015 to 2018 at Viet Duc Hospital. Results: 20 failure cases caused by loosen stem or acetabular implant, or worn acetabulum; 3 failure cases caused by femoral shaft fracture just below stem and the other had stem neck fracture. 9 cases had performed total hip replacement, 6 cases were replaced acetabular implant and 8 cases had to be replaced stem. Hip function improved significantly better in total: 17 good and 6 fair. Conclusions: Early detection defective artificial hip and revision hip replacement can help improve hip function.

Keyword: revision hip arthroplasty

\section{I. ĐăT VẤN ĐỀ}

Kỹ thuật thay khớp háng nhân tạo cho các khớp háng bị hỏng là một tiến bộ lớn về mặt kỹ thuật, giúp cải thiện tốt mức độ đau khớp, phục hồi tốt chức năng khớp háng, giúp người bệnh sinh hoạt bình thường. Sau khi thay khớp háng xuất hiện những thay đổi cấu trúc xương xung quanh khớp nhân tạo làm ảnh hưởng tới kết quả cũng như tuổi thọ khớp háng như hiện tượng lỏng chuôi, các ố tiêu xương quanh ổ cối hay chuôi khớp háng, hiện tượng mòn khớp hay do sai sót về kỹ thuât như lỏng khớp, khớp có tư thế không đúng dẫn tới trật khớp hay mỏi khớp, nhiễm trùng... [1] Mặt khác, mỗi loại khớp háng có một tuối thọ nhất định nên khớp háng nhân tạo không tồn tại vĩnh viễn. Do vậy cần phải phát hiện các dấu hiệu hỏng khớp háng để thay thế khớp háng kịp thời giúp cải thiện chức năng của khớp háng. Thay lai khớp háng là thay lại 